\title{
ON THE PARADOXES OF TEACHING DIGITAL ANTHROPOLOGY ONLINE: REFLEXIVE PEDAGOGY AND THE CHALLENGES OF INVOLUNTARY ONLINE LEARNING
}

\author{
Anna Apostolidou, Panteion University and Hellenic Open University, Greece
}

\begin{abstract}
The paper examines the heightened role of reflexive pedagogy and the challenges of participation that came as a result of the sudden transition of conventional higher education into an exclusively online modality during the 2020 covid-19 pandemic. Drawing on the cultural and educational context of Greece, the paper focuses on the case study of an undergraduate course in Digital Anthropology at Panteion University and details the challenges that were met creatively by the students and the instructor. To that end it employs an ethnographic study of the classroom, and discusses students' testimonies from the weekly online evaluation that was performed during the spring term 2020 along several axes of participation which include: participation in numbers; participation in active dialogue; participation in (collaborative) coursework using multimedia format; participation in ongoing evaluation; silent and invisible participation. The analysis is contextualized in the unprecedented social and educational conditions of the pandemic and its repercussions on the shifting roles and performances of students and instructors.
\end{abstract}

Keywords: reflexive pedagogy, student participation, online evaluation, digital anthropology

\section{Introducing problematics and methods in an unprecedented context}

This paper details the sudden shift that occurred in the class dynamic when, in March 2020, we had to transfer all academic activity online due to the covid-19 pandemic. At the beginning of term, after one introductory face to face meeting with students of the Digital Anthropology undergraduate course at the Anthropology Department of Panteion University (Athens, Greece), the measures that the Greek government deemed necessary for the prevention of the virus outbreak forced all universities to hold lectures, meetings and administrative procedures through instant messaging and videoconferencing software (such as Skype for Business, Teams, Zoom etc.) 


\section{Apostolidou, A.}

On the Paradoxes of Teaching Digital Anthropology Online: Reflexive Pedagogy and the Challenges of Involuntary Online Learning

This sudden shift brought about a series of noticeable obstacles on the part of instructors who lacked previous experience with distance learning modalities: the lack of training and familiarity of academic staff with digital technologies; the reaction to top-down political decisions that gravely affected the day-to-day practices and the long term shifts which derived from the transfer of educational activity into online environments; the fear that this situation would signal permanent changes that would heighten professional precarity in the academia in a neoliberal logic. On the other hand, the students expressed similar anxieties: unequal access to digital technologies or inadequate training was reported to be a very intimidating factor, at least at first, along with the fear that precious immediate contact with peers and teachers would diminish the quality of studies and that ultimately the academic term would be lost. Such concerns lasted throughout the term (which was held and evaluated entirely online), but on the present paper I will be focusing on what seemed to me to be a 'positive' side of this social and educational turmoil. The questions raised regard the heightened role of reflexive pedagogy in the digital environment as well as the different forms of participation enabled by this unique contingency, mainly based on reflexivity, experimentation and collaborative learning.

Methodologically, I followed a standard practice in the anthropology of education, placing myself at the position of the instructor and team coordinator and at the same time performing online participant observation, journal keeping and collecting digital traces from the weekly lectures/meetings with students. The latter consist in images, feedback forms, chat discussions in the Skype for Business environment, blog posts etc. The observation lasted three months (early March to early June), and the research questions were admittedly formed along the way. At the end of term, I analysed the collected data on the axis of student participation and reflexive learning. The student population of the class varied from 117 to 38 participants (312 being officially registered in the class), with a rough gender ratio (male/female) of one to four, aged 20 to 25 with a few older students, ranging from 30 to 50 years of age. With the exception of two students, all were Greek native speakers. Unfortunately, the collected data cannot account for the persons who never attended the online meetings, and/or participated in the chats, the evaluation forms, the presentations or the collaborative activities and exercises performed throughout the term. The overall evaluation was very good, ranging from 4 to 5 points (in standard 5-point Likert scale) for the top $75 \%$ of the class participants. The strategies that I employed in order to cope with the situation was to try and create a supportive, non-judgemental and less formal learning environment, to encourage participation through paper presentations, short research exercises and multimodal communication and to utilize students' experiences in order to make use of their situated, authentic and constructive learning capacities. Given all of the above, it needs to be noted that, ironically, the specific course coincided perfectly 


\section{Apostolidou, $A$.}

On the Paradoxes of Teaching Digital Anthropology Online: Reflexive Pedagogy and the Challenges of Involuntary Online Learning

with the forced online contingency. As a student observed: "I was really intrigued by your research in digital ethnography and this lesson gives us the opportunity to imagine the empathy between the subjects under study”.

\section{The various facets of participation}

\section{Participation in numbers}

As a rough first indicator of student participation, the course had a steady audience of around 60 persons with certain ups and downs depending on the point in time (beginning/end of term etc.) and other time-related factors. Apart from lectures, presentations, discussion and other activities, at the end of every meeting participants were given a link and were asked to fill in an online form with two questions (How was your overall impression from today's meeting? Would you like to contribute any other comments?) which, as I explained, would help me keep communication channels open and identify areas of interest that could be improved, fine-tuned or incorporated in the course. Even though I asked students to give a numeric (Likert scale) representation of their overall impression of each class meeting, this was taken as a mild indication and was not treated statistically but only as a supplementary tool for guiding the preparation of the next class or coursework.

Table 1: Numeric representation of student participation in synchronous online instruction throughout term

\begin{tabular}{lccc}
\hline Course week & $\begin{array}{c}\text { Participants in } \\
\text { class }\end{array}$ & $\begin{array}{c}\text { Participants in } \\
\text { evaluation }\end{array}$ & $\begin{array}{c}\text { Participation } \\
\%\end{array}$ \\
\hline Week 3 (Initial feedback and preferences & $\begin{array}{c}312 \text { registered } \\
\text { (c.50 attended) }\end{array}$ & 81 & 26 \\
form) & 98 & 32 & 33 \\
Week 4 (Lecture/meeting \& evaluation) & 117 & 31 & 26 \\
Week 5 (Lecture/meeting \& evaluation) & 38 & - & - \\
Week 6 (Informal online meeting) & 56 & 26 & 46 \\
Week 7 (Lecture/meeting \& evaluation) & 61 & 13 & 21 \\
Week 8 (Lecture/meeting \& evaluation) & 49 & 12 & 25 \\
Week 9 (Lecture/meeting \& evaluation) & 101 & 38 & 38 \\
Week 10 (Final meeting \& extended & & & \\
evaluation) & & & \\
\hline
\end{tabular}

As indicated in the above table the participation in the online evaluation was impressively stable and accounted for almost one fourth of the student population, which, compared to past observations, was indeed facilitated by the digital component of instantly sharing the link and filling in the form right after the closing remarks of the meeting. Also, and perhaps more importantly, students were able to express opinions in short written form and anonymously, being at the same time informed that one's opinion is important and formative of the course they partake in. 


\section{Apostolidou, $A$.}

On the Paradoxes of Teaching Digital Anthropology Online: Reflexive Pedagogy and the Challenges of Involuntary Online Learning

\section{Dialogic and collaborative participation}

Another important observation is that the multimedia format of the class acted as a liberating factor, unleashing the critical and creative potential of many students who, according to their account, would never dare create a PowerPoint or video presentation for an undergraduate course or contribute jokes and casual anecdotes in a padlet and had rarely before worked together with classmates in order to build something (a digital artefact, a blog, a podcast etc.). This potential was expressed in-class with vivid verbal and written dialogue among the students (even though some were consistently more talkative than others) but it was also noted in the mid and final evaluation forms. This collaborative strand was also visually and multimodally encouraged, as one of the first thing I asked in our first impromptu online meeting was to share a photo of their surroundings in order to co-create the class environment and share it among ourselves. Another component that was highly appreciated was the inclusion of two or three 15-minute presentations of articles, videos and digital artefacts that was performed in a collective and reflexive manner. As students testified: "It made the class less monotonous", "Our classmates' presentations were finely prepared and very interesting- thank you!" "The constant dialogue that existed between the teacher and the students and the fact that our own voice could be heard, about things that were related to the lesson and on a more practical level."
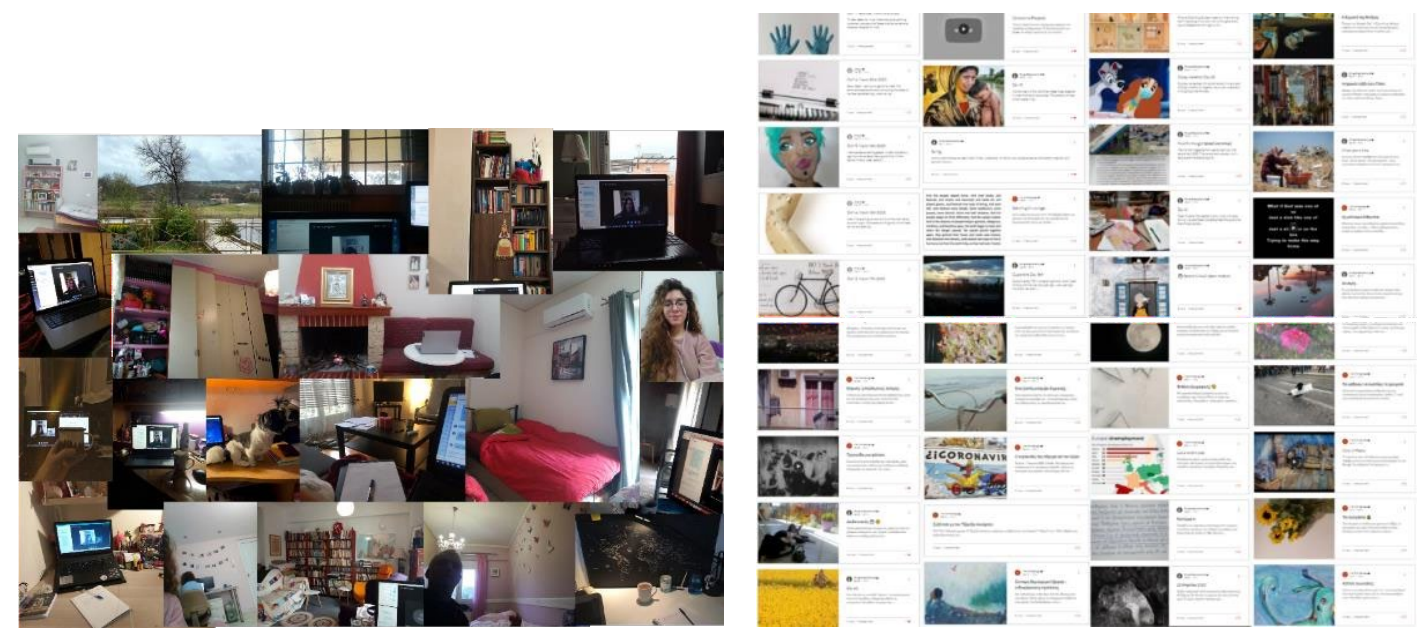

Figures 1, 2. Our classroom digital collage meeting \& Selected samples from the collective course blog (https://annapostolidou.wixsite.com/viralanthro/blog)

The interaction and the multisensory stimulus was another parameter that was positively commended upon ("It made me feel alive in the context of extreme hardship that we are going through!" Your class and everything we see and learn through it, as well as the energy and liveliness that we see reproduced on our screen is the reason that I give up my sleep -which I love- every Friday") whereas some students found it more difficult to keep up with the flow of information ("Too much information", "I couldn't keep notes as usual", "The conditions under which the class is taught makes it difficult for me", "I wish we had 


\section{Apostolidou, A.}

On the Paradoxes of Teaching Digital Anthropology Online: Reflexive Pedagogy and the Challenges of Involuntary Online Learning

less visual stimuli and got deeper on some of the issues raised"). As a student summarized it: "Many courses these days are to some extent an extra burden that we all have to bear students and teachers. There is a perplexity in how to share knowledge, an injustice in who speaks and who does not, and, in general, the desired result cannot be achieved everywhere. These days when so many things are different - and for many in more unpleasant ways than others - lessons turn into obligations that we must meet, while at the same time finding it difficult to fulfil many other, and perhaps more basic, aspects of our lives. But with this lesson it is not so. It's like a Skype 'with friends', and the teacher's figure is just the figure of that friendly person who wants to share a new, exciting knowledge and information with us, and to do so in such a dialectical way, that it impresses. It is difficult to feel intimate and to be with trusted people in a dark background that frighteningly illuminates the ' 96 participants', but in this lesson we succeed, and I look forward to the next lecture each time... (Sorry I wrote so much, but anonymity opens up the possibility of things being said outside the 'wooden' [formal] writing of emails, and gives me the opportunity to express my thoughts honestly)."

\section{Hesitant, subtle and silent participation}

This mode of participation was achieved in two distinctive ways. The first one was my proposition that those who wished to participate in the class chat but were reluctant to do so with their name and surname visible to other participants might at any time disconnect and reconnect to the teleconferencing with a pseudonym. This was a defining factor that helped a small albeit important percentage of the students to offer comments, links, ideas and criticism without being identified by their names or showing their face on camera. This was indeed an extremely encouraging finding, one that in my view is worth pursuing further in our educational practices, following an anthropological tradition of 'protecting' our interlocutors' identities and sense of integrity. The second way of students contributing to the classwork and ongoing discussion was the creation of the course blog, which I set up during the first days of the lockdown and swiftly after handed over to a student who expressed an interest in acting as an administrator for the duration of the term. Even though timid at first, the participation of anonymous and eponymous posts from class members exceeded my initial expectations and resulted in a polyphonic, heterogeneous and intriguing weblog that stretched thematically from the quarantine to the coursework and beyond.

Another initiative worth mentioning is that we arranged to meet for an online afternoon tea, which brought us much closer. Even though only 38 persons participated (it was not a course prerequisite and it was held during Eastern Holidays), the interaction was much less informal, much more inquisitive and helped us 'rehearse' many of the ideas we 


\section{Apostolidou, A.}

On the Paradoxes of Teaching Digital Anthropology Online: Reflexive Pedagogy and the Challenges of Involuntary Online Learning

touched upon in the overall discussion, like techno-sociality, social presence and collaborative work. The impressive finding from this meeting is that only 9 out of 38 persons opened their mics and cameras to contribute to the informal discussion, the majority of those who entered the meeting stayed throughout the 3 hours and maintained a silent and stable "presence", which was noticeable by all of the class members who shared their thoughts. On this particular occasion I forgot to provide an evaluation link in the last minutes of our meeting and posted it afterwards on the LMS platform, where no one filled it in. The discussion and dialogue encouraged by myself and some of the more talkative students assisted others to participate, if silently, to the overall communication and team building ("The class had great interaction and this makes it different", "Great vibe, great ideas-thanks!", "I loved the fact that we could pose questions and have short discussions through the chat without interrupting you or our classmates who were giving presentations", "Nice atmosphere, loved the interaction provided through the comments"). Finally, there were those who partook in all class activity, but did so in their own terms: "I personally decided not to answer the questionnaire, as I think it would distort the results a bit. The questionnaire worries me because it is very similar to what we would complete in class, under normal conditions. To make it more understandable, I do not think that the course as you planned it had a problem, however, the online course deprived me of what life offers."

\section{Reflexive pedagogy in a digital context}

The aforementioned ways of participation brought about another crucial question on the instructional design of this peculiar term, which required a limited theoretical consideration. Drawing from my background in constructivist, situated and transformative pedagogical paradigms I decided to turn my focus exclusively on the concept of reflexivity and try to cultivate reflexive and self-reflexive thought, as an integral part of anthropological inquiry, and teaching. Ryan (2014) discusses the different personal epistemologies of teachers and students, which are central not only to the process of individual learning, but also to the transformation and re-making of culture; as such, they impact ways of knowing and acting, negotiation of previous experiences, capacity building and interaction with the social and sensory world, to shape how one learns. Drawing on Archer's body of work, she identifies various reflexive modalities (e.g. absolutist, subjectivist, evaluativist) that guide autonomous or communicative reflexivity and are intrinsic to meaningful learning. While it is rather utopian to support that one can effectively identify and sort out these learning epistemologies in large and unstable groups of students, these acted as guiding typologies that helped shaped the various different ways I attempted to encourage reflexive learning in class. Reflection has been variously defined from different perspectives (e.g. critical theory or professional practice) and disciplines (see 


\section{Apostolidou, A.}

On the Paradoxes of Teaching Digital Anthropology Online: Reflexive Pedagogy and the Challenges of Involuntary Online Learning

Boud 1999), broadly covering two key elements: (a) making sense of experience; and importantly, (b) reimagining future experience. This definition reflects the belief that reflection can operate at a number of levels, and suggests that to achieve the second element (reimagining), one must reach the higher, more abstract levels of critical reflection. Ryan (2014; pp.14-15) refers to this type of reflection as academic or professional reflection, which involves learners making sense of their experiences in a range of ways by: understanding the context of learning and the particular issues that may arise; understanding their own contribution to that context, including past experiences, values/philosophies and knowledge; drawing on other evidence or explanation from the literature or relevant theories to explain why these experiences have played out or what could be different; and using all of this knowledge to re-imagine and ultimately improve future experience and social structures. This is exactly what we attempted to achieve, by treating everyday news, experiences, course material, interactions, and obstacles as opportunities for personal and collective contemplation and leaving the curriculum to work in the background.

It soon became apparent that contemporary learners value increased reflexivity that attends to contoured experiences and multimodal meaning-making. Our "pedagogical orientations" (Abrams, 2015; p.37), which represent the relationship among socioculturally situated understandings and discoveries and the (re)creation and/or transformation of meaning and artifacts, helped to shed light on the needs of current and future physical and digital citizenship. We employed various approaches such as learning by design (Arvanitis, 2018), learning through artefact reflection (Ryan, 2014) and employing authentic learning. Paramount to this approach is that the teacher learns to function as a member of a collegiality, developing a collective intelligence and engage in knowledge processes such as experiencing, theorizing, analysing and implementing (Kalantzis \& Cope, 2012). In this effort, we often used visual stimuli as critical visual inquiry, in the logic that spectacle strategies in learning entail great engagement, echoing Merleau- Ponty's experiential position, and allowing for learning moments to become transformative possibilities through physical, emotional, and intellectual triggers. As offered in the evaluation: "The presentations, the non-strict style of the lesson, the continuous feedback, the blog, the visual 'teasers' of the lesson, the constant dialogue that existed between the teacher and the students. I also saw a different perspective on the digital world and became acquainted with digital anthropology, which I initially did not particularly like as I had a distorted knowledge of its subject matter.”

Indeed, the main principle of the E-Learning 2.0, or digital turn in higher education signals the digital shift from teaching to Learning, termed "Digitalization of Teaching and Learning", which requires to invent a technical infrastructure as well as didactical 


\section{Apostolidou, A.}

On the Paradoxes of Teaching Digital Anthropology Online: Reflexive Pedagogy and the Challenges of Involuntary Online Learning

counselling for teachers and learners, so that digital-based learning can be realized (Kergel et al., 2018). In this context, open approaches to digital literacy are conceptualized and practically encouraged in higher education, especially based on sociocultural models of digital literacy and practice (Gruszczynska et al., 2013). In-class participant observation becomes here a great opportunity to address teachers' and learners' preconceptions and ways of knowing, apprehending and learning as well as sharpening our/their "reflexive reflexes" as future anthropologists. In a sense, the pandemic gave many students the chance to rehearse artful or collaborative auto-ethnography, termed by some "digital reflection" or "digital bricolage" in the sense of using digital media to bring together the learning and imaginative capacities of students who creatively employ arts-based methodologies to learn, interact and perform in a con-conventional academic environment. In this case, as testified, this created multiple channels of communication: "It was so far the only lesson in which we have done so many small but creative activities that really filled me with thoughts and reflections. A lesson that I will remember both because of the experience of incarceration and the special atmosphere of the lesson itself. Open, accessible, natural and friendly.”.

However, as Iszatt-White et al. (2017) point out, the desire to engage students in reflexive learning interventions and to disrupt the power asymmetries and hierarchical dependencies of more traditional educator-student relationships often results in highlighting those very asymmetries and dependencies. Successful resolution of such a paradox depends on the ability of educators to undo their own reliance on authority underpinned by a sense of theory-based expertise. This concept of "distributed teaching responsibility" (Guri-Rosenblit, 2011) was a useful guiding line for my own practice and it seemed to have a relaxing and bonding effect in the course team, made evident by various oral and written comments offered by students. Indeed, as Arvanities notes (2018; p.116) transformative education rethinks agency as the "relations between expert knowledge sources (teachers and authoritative texts) and novices (learners) are reconfigured" (Kalantzis \& Cope, 2012; p.273) and reflexivity is perceived on the basis of reciprocity, and more often than not the reversal of roles, e.g. teachers as learners and learners as teachers (Arbams, 2015; p.38). This process requires an 'identity undoing' in the part of educators, which is found to have strong connections to the impact on identity of power relations, resistance and struggle.

Novel approaches such as feminist data studies (Leurs, 2017) call for a reflexive and powersensitive data scholarship that does not misrecognise the gender, race, geography and crypto-colonial skews in big data and quickly digitalization of the university. In that respect, the evaluation indicated that students greatly appreciated a professor for her social presence online (for "being there", giving positive energy), for valuing their viewpoint 


\section{Apostolidou, A.}

On the Paradoxes of Teaching Digital Anthropology Online: Reflexive Pedagogy and the Challenges of Involuntary Online Learning

(feedback forms being one way that this was demonstrated), and for establishing a supportive and open overall atmosphere, with constant and easy-going communication. Apart from the flow of information and the risk of sharing and showing too much on each class, the pace of the discussion was also dictated by many comments I received ("Please when you pose a question allow for more time so that those of us who are less courageous and may need a bit more time to overcome the mic/camera/stage fright and participate”).

However, this is not an uncomplicated task for educators worldwide. According to Schlusmans et al. (2004) the organizational approaches of a classroom-based teaching are closely aligned with artisan or craftsman practices where the academics are responsible for the entire development and delivery process of their courses. In comprehensive online teaching frameworks, as well as in large-scale distance teaching universities, the academics are required either to assume new roles or to collaborate in a team framework with tutors, editors, instructional designers, television producers, computer experts, graphic production personnel, etc. in developing and delivering their courses (Guri-Rosenblit, $2011 ;$ p.21). It is notable that professors who view the academic freedom in teaching as a sacred value of their profession, resist strongly the unbundling of their teaching responsibility and the participation in a team framework (Guri-Rosenblit, 2011; p.22), which is further enhanced by lack of support infrastructures and often adequate technological literacy.

Returning to the empirical discussion, in the case study under scope, two more questions from the evaluation stand out in terms of the students' account of their reflexive cultivation. In the first "To what extent did this course help you to experience your position in the training team differently?" Out of the 37 responses, 22 rated it 3 (not really), 51 rated it 4 (considerably) and another 22 rated it 5 (very much). In the question "To what extent did this course help you change the way you think about some issues related to anthropology?" the responses were quite similar: 23 answered 3 (not really), 51 answered 4 (considerably) and 23 rated 5 (very much). For me this was a strong indicator that the novel character of the course's approach acted at a deep reflexive level and created the conditions for much-needed experimentation and introspection during a troubled period of time. Moreover, as other studies illustrate, including feedback from students provides evidence that diversification of communication within teaching and learning practice gives students more choice and opportunity to interact with both their peers and teaching staff (Young \& Nichols, 2017). As a student astutely noted: "[What I valued the most was] a tendency to do things that never happened before". 


\section{Apostolidou, $A$.}

On the Paradoxes of Teaching Digital Anthropology Online: Reflexive Pedagogy and the Challenges of Involuntary Online Learning

\section{Implications for "real lessons" online}

Ryan (2013) argues for a reflexive pedagogical balancing act of attending to different levels of reflection (i.e. Reporting and responding, Relating, Reasoning, and Reconstructing) as a way to stimulate focused, thoughtful and reasoned reflections that show evidence of new ways of thinking and doing. He notes that, while the goal of academic or professional reflection is generally to move students to the highest level of reflection to transform their learning/practice, unless higher education teachers attend to every level of reflection there are specific, observable gaps in the reflections that students produce. Balancing my efforts and attending to all four levels was the centre of my focus throughout the term; additionally, the final evaluation of the Digital Anthropology course included questions that addressed all four levels, however difficult to measure, numerically or otherwise.

The implications of this example indicate that sometimes sudden changes in the parameters of learning may have a positive effect in the process. In fact, leaps may be observed in the sensibilities that co-construct learning in the university when a major factor, such as face to face contact, is no longer an option. Designing open, reflexive, task-oriented and collaborative pedagogy in higher education, engulfing accessible digital practices when possible is a complicated task which needs to be backed by scaffolding activities and consistent supportive initiatives. Indeed, the issue of student support for reflexive and emotional interactions was proven to be paramount, as is the case in other sociocultural pedagogical contexts (Augustsson, 2010). This type of purposeful reflection, which is generally the aim in higher education courses must ultimately reach the critical level for deep, active learning to occur. Such reflection is underpinned by a transformative approach to learning that sees the pedagogical process as one of Mezirowian knowledge transformation and emancipation rather than knowledge transmission (Ryan, 2014; p.18). As a young student remarked in response to the question "What will stay with you most from this term's overall experience?": "These meetings, which included discussions from our experience and daily life, and a more general dialogue, were more essential than a simple lesson. They changed the ways we think about ourselves and anthropology, and they were not just presentations, but a real lesson!"

\section{References}

Abrams, S. S. (2015). Digital resources, reflexive pedagogy, and empowered learning. In Cope, B. \& Kalantzis, M. (Eds.), A pedagogy of multiliteracies: Learning by design (pp. 37-48). London: Palgrave Macmillan.

Arvanitis, E. (2018). Preservice teacher education: Towards a transformative and reflexive learning. Global Studies of Childhood, 8(2), 114-130. 
Augustsson, G. (2010). Web 2.0, pedagogical support for reflexive and emotional social interaction among Swedish students. The Internet and Higher Education, 13(4), 197205.

Gruszczynska, A., Merchant, G., \& Pountney, R. (2013). Digital Futures in Teacher Education: Exploring Open Approaches towards Digital Literacy. Electronic Journal of e-Learning, 11(3), 193-206.

Guri-Rosenblit, S. (2011). Digital technologies in higher education: Sweeping expectations and actual effects. Nova Science Publishers, Inc.

Iszatt-White, M., Kempster, S., \& Carroll, B. (2017). An educator's perspective on reflexive pedagogy: Identity undoing and issues of power. Management Learning, 48(5), 582-596.

Kalantzis, M., \& Cope, B. (2012). New Learning: Elements of a Science of Education. New York: Cambridge University Press.

Kergel, D., Heidkamp, B., Telléus, P. K., Rachwal, T., \& Nowakowski, S. (2018). The digital turn in higher education: International perspectives on learning and teaching in a changing world. Springer VS.

Leurs, K. (2017). Feminist data studies: using digital methods for ethical, reflexive and situated socio-cultural research. Feminist Review, 115(1), 130-154.

Ryan, M. (2013). The pedagogical balancing act: Teaching reflection in higher education. Teaching in Higher Education, 18(2), 144-155.

Ryan, M. (2014). Teaching reflective learning in higher education. Springer International Publishing. 